\title{
The efficacy of gemcitabine alone versus gemcitabine plus cisplatin in the treatment of metastatic pancreatic cancer
}

\author{
Metastatik Pankreas Kanserinde Gemsitabin-Sisplatin Kombine \\ Kemoterapisi Etkinliğinin Yalnızca Gemsitabin Kemoterapisi ile \\ Karşılaştırılması
}

\author{
Gökmen Umut Erdem ${ }^{1}$, Mutlu Doğan ${ }^{1}$, Zeynep Tuğba Güven ${ }^{2}$, Nebi Serkan Demirci ${ }^{1}$, Yakup \\ Bozkaya $^{1}$, Nurullah Zengin ${ }^{1}$ \\ ${ }^{1}$ Ankara Numune Eğitim ve Araştırma Hastanesi, Tıbbi Onkoloji Kliniği, Ankara, Türkiye \\ ${ }^{2}$ Ankara Numune Eğitim ve Araştırma Hastanesi, Dahiliye Kliniği, Ankara, Türkiye
}

\section{ÖZET}

GÍRIŞ ve AMAÇ: Bu çalışmanın amacı metastatik pankreas kanserinin tedavisinde gemsitabin-sisplatin (GP) kombine kemoterapisine (KT) karşı gemsitabin $(\mathrm{G})$ kemoterapisinin etkinliğini değerlendirmektir.

YÖNTEM ve GEREÇLER: Nisan 2005 ile Kasım 2015 tarihleri arasında merkezimizde histopatolojik olarak adenokarsinom tanısı almıs metastatik pankreas kanserli hastalarda progresyonsuz sağkalıma (PS) ve genel sağkalıma (GS) etki eden faktörler (klinikopatolojik özellikler, tedaviler, bazal tümör markırları, serum albümin, kreatinin ve bilirubin düzeyleri) retrospektif olarak değerlendirildi.

BULGULAR: Üç kür ve üzerinde KT alan toplam 99 hastanın (74 hasta GP, 25 hasta G) yanıt değerlendirmesi yapıldı. Gruplar demografik özellikleri açısından karșılaştırıldığında kombine KT alan hastalar daha genç, daha iyi ECOG performans skoruna ve daha az komorbid hastalığa sahipti. Hastaların \%41.4’ü progresyondan sonra ikinci basamak KT almış olup, bu G grubunda \%28.0, GP grubunda ise \%45.9'du. GP ve G grupları arasında GS farkı saptanmadı (sırasıyla; 8.3 aya karşı 6.0 ay, $\mathrm{P}=0.13$ ). Ortanca PS GP alan hastalarda $\mathrm{G}$ alan hastalara kıyasla daha uzundu (sırasıyla; 5.1 ay ve 3.9 ay, $\mathrm{P}=0.01$ ) ve bu fark çok değişkenli analizle de doğrulandı. ECOG performans skoru daha iyi (8.3 aya karş1 6.3 ay) ve ikinci basmak KT alan hastalar (12.1 aya karşı 5.9 ay) daha uzun GS ile ilişkili saptand1.

TARTIŞMA ve SONUÇ: Gemsitabin-sisplatin tedavisi ile daha iyi PS elde edilirken GS farkı istatiksel olarak anlamlı değildi. Tanı anında ECOG performans durumunu daha iyi ve ikinci basamak KT alabilen hastalar daha iyi genel sağ kalıma sahiptir.

Anahtar Kelimeler: Pankreas kanseri, Gemsitabin, Sisplatin

\begin{abstract}
INTRODUCTION: The purpose of this trial was to evaluate the efficacy of gemcitabine $(\mathrm{G})$ alone versus gemcitabine plus cisplatin (GP) in the treatment of metastatic pancreatic cancer.

METHODS: In ninety-nine patients with a histopathologically confirmed diagnosis of metastatic pancreatic cancer from April 2005 to December 2015, factors affecting progression-free (PFS) and overall survival (OS) (clinicopathological features, treatments, basal tumor markers, serum albumin, creatinine and bilirubin levels) were retrospectively evaluated.

RESULTS: Response evaluations were performed in 99 patients (74 patients for GP group, 25 patients for G group) who received three cycles and more chemotherapy (CT). When the groups were compared in terms of their demographic characteristics, the patients in the group receiving GP were younger with a better performance status and had less comorbid disease. About $41.4 \%$ of the patients received second line CT after progression $(28.0 \%$ in the G group, $45.9 \%$ in the GP group). The median OS was 8.3 months in the GP group and 6.0 months in the G group $(\mathrm{P}=0.13)$. The median PFS was 5.1 months in the GP group and 3.9 months in the $\mathrm{G}$ group $(\mathrm{P}=0.01)$. In multivariate analysis, combination CT was associated with longer PFS (5.1 vs. 3.9 months). Patients with a good performance status ( 8.3 vs. 6.3 months), and those who received second-line CT (12.1 vs. 5.9 months ) were associated with longer OS.
\end{abstract}


DISCUSSION AND CONCLUSION: Compared with G, GP significantly improved PFS without any significant difference in OS. Patients with a good performance status and those receiving second-line CT had longer median OS.

Keywords: Pancreatic cancer, Gemcitabine, Cisplatin

\section{GíRiş}

Pankreas kanseri, dünyada kanser ölümlerinin önde gelen nedenlerinden biridir. Hastaların yaklaşık yarısı metastatik dönemde tanı alır ve 5 yıllık sağkalım oranları \%2.7'dir (1). Metastatik pankreas kanseri için günümüzde Ulusal Kapsaml Kanser Ağl(National Comprehensive Cancer Network, NCCN) ve Avrupa Medikal Onkoloji Topluluğu (European Society for Medical Oncology, ESMO) klavuzlarında FOLFIRINNOX (folinik asid, 5fluorourasil, irinotekan, ve oksaliplatin) ve Nabpaklitaxel (nano parçacıklı albümin bağgl paklitaksel)-Gemsitabin standart tedavi olarak önerilmektedir $(2,3)$. Yaş, performans durumu ve diğer klinik faktörler göz önüne alındığında kombine kemoterapi (KT) almaya uygun olmayan hastalarda ise gemsitabin $(\mathrm{G})$ tercih edilir (3).

Pankreas kanseri KT dirençli kanserlerden birisidir. Yapılan preklinik çalışmalarda gemsitabinin sisplatinin neden olduğu DNA hasarını artırdığı gösterilmiştir (4, 5). Yapılan metaanalizlerde de Gemsitabin ve sisplatin (GP) kombinasyonu, G monoterapsi ile karşılaştırıldığında sağkalım yararı gösteren (6) ya da göstermeyen $(7,8)$ sonuçlar mevcuttur.

Ülkemizde toksisitesi (FOLFIRINOX) ve ilaca birinci basamakta erişim zorluğu (nabP) nedeni ile performansı kötü hastalarda $G$, performans1 daha iyi olan hastalarda ise $\mathrm{G}$ ile kombine rejimler tercih edilmektedir. Çalışmamızın retrospektif olması ve yeni tedavi seçenekleri nedeni ile lokal ileri hastalık grubu dışlanarak metastatik hastalıkta $G$ ile GP tedavisinin etkinliği değerlendirmeyi amaçladık.

\section{MATERYAL VE METOT}

Nisan 2005 ile Kasım 2015 tarihleri arasında histopatolojik olarak (primer kitle ya da metastaz bölgesinden) pankreas adenokarsinom tanısı almış metastatik pankreas kanserli hastalar retrospektif olarak değerlendirildi.

ECOG performans skoru 2 ve altında, 18 yaş üzerinde, daha önce KT almamış, yeterli renal, hepatik ve hematolojik fonksiyonlara sahip (mutlak nötrofil sayıs1 $>1500 / \mathrm{mm}^{3}$, trombosit say1s1 $>100000 / \mathrm{mm}^{3}$, total bilurubin, AST, ALT $<1.5 \times$ normalin üst sinırı, serum kreatinin düzeyi $<1.25 \mathrm{x}$ normalin üst sınırı), ez az 3 kür KT almış olan metastatik pankreas kanserli hastalar çalışmaya alındı. Adenokarsinom dışı patolojiye sahip olan, G temelli KT dışında tedavi alan, ikinci primer malignitesi olan, ciddi comorbidite, aktif enfeksiyonu olan hastalar çalışma dışı bırakıldı. Hastaların demografik özellikleri, birinci ve ikinci basamak tedavide aldığ 1 tedaviler, KT ilişkili toksisite, takipler sırasında görülen progresyon ve ölüm açısından değerlendirildiler. Sağkalıma etki eden prognostik faktörler araştırıldı. Hastaların son durumları son kontrol tarihlerine göre ve hastane ölüm kayıt bildirim sistemi incelenerek belirlendi.

\section{Tedavi ve toksiste değerlendirilmesi}

Tedavi şemasında; G: $1000 \mathrm{mg} / \mathrm{m}^{2} \mathrm{KT}$ 'nin 1 . ve 8. gününde her 3 haftada bir uygulandı. GP: [G: $1000 \mathrm{mg} / \mathrm{m}^{2} 1$. ve 8 . günler] $+\left[\mathrm{P}: 75 \mathrm{mg} / \mathrm{m}^{2} 1\right.$. gün], 3 haftada bir uygulandı. Tedavi hastalık progresyonu, kabul edilemez toksisite ve hastanın tedavi reddi istemesi durumunda kesildi. Dozların modifikasyonu (\%25'e kadar) ve ertelenmesi, hematolojik veya nonhematolojik toksik olaylara uygun olarak düzenlendi. Üç kür KT sonunda (her 8 haftada bir) tam, parsiyel ya da stabil hastalık gösteren hastaların tedavisine devam edildi. Ek olarak, herhangi bir KT döngüsünden sonra klinik durumu bozulan hastalar radyolojik olarak değerlendirildi. Radyolojik ilerleme oluşursa, tedavi kesildi.

\section{İstatistiksel analiz}

İstatistiksel analizde SPSS 18.0 (Statistical Package for Social Sciences, Chicago, IL, USA) kullanıldı. Parametreler ki-kare testi ile kıyaslandı. Sağkalım analizi Kaplan- Meier yöntemi ile yapıldı ve istatistiksel farklar Logrank testi ile doğrulandı. Sağkalım üzerine etkili faktörleri ortaya çıkarmak için tek değişkenli ve 
çok değişkenli Cox regresyon analiz modeli uygulandı. $\mathrm{P}<0.05$ değeri anlamlı kabul edildi.

\section{BULGULAR}

Hastaların karakteristik özellikleri Tablo 1'de özetlendi. Toplam 145 metastatik pankreas kanserli hastanın, 130'una (\%89.2) birinci basamak KT uygulanmış olup bunların 122'si G ve GP içeren KT almıştı. Bu hasta grubunun da 99'u (\%81.1) en az 3 kür KT almıştı. Çalışmaya dahil edilen 99 hastanın tanı anında ortanca yaşı 59 yıl (aralık; 28-80) ve erkek/kadın oranı 2.8:1 (73 erkek, 26 kadın) idi. ECOG performans durumuna göre hastalar değerlendirildiğinde 57 hasta (\%57.6) ECOG 0-1, 42 hasta (\%42.4) ECOG 2 performansa sahipti. Ailesinde birinci derecede akrabalarında pankreas kanseri olan 3 (\%3.0) hasta mevcuttu. Hastaların \%60'ında sigara kullanımı mevcut olup, \%46'sinda komorbid (diabetes mellitus, hipertansiyon, kronik obstriktif akciğer hastalığı) hastalık mevcuttu. Tümör yerleşim yeri sırası ile baş, kuyruk ve gövde kısmındaydı. En sık metastaz yeri karaciğerdi (\%87.9).

Hastaların 25'ine (\%25.3) G, 74'üne (\%74.7) GP KT'si verildi. Gruplar demografik özellikleri açısından karşılaştırıldığında GP alan grupta hastalar daha genç ( ortanca yaş 56.5 ve 70 yaş, $\mathrm{P}<0.001)$, daha iyi ECOG performans skoruna (\%66.2 ve \%32.0, $\mathrm{P}=0.003)$ ve daha az komorbid hastalığa sahipti (\%39.2 ve \%68.0, $\mathrm{P}=0.01$ ).

\section{Toksisite}

Hastalar grade 3-4 hematolojik toksisite açısından değerlendirildiğinde grade 3-4 anemi, trombositopeni ve nötropeni istatiksel olarak anlaml1 olmamakla birlikte kombinasyon kolunda daha fazlayd 1 (sirasi ile $\% 10.8 \& \% 8.0$, $\% 16.2 \& 4.0, \% 16.2 \& \% 8.0)$.

\section{Etkinlik ve Prognostik faktörler}

Hastaların ortanca takip süresi 7.1 ay olup, bu süre $\mathrm{G}$ alan hastalar için 6.0 ay, GP alan hastalar için 8.3 aydı. Analiz sırasında hastaların hepsinde progresyon gelişmiş olup yaşayan hatsa yoktu. Hastaların \%41.4'ü progresyonda ikinci basamak KT almış olup, bu G alan grupta $\% 28.0$, GP alan grupta \%45.9'du.

Genel cevap oranı G kolunda \%16.0, GP kolunda \%37.8'di. Hastalık kontrol oranı ise

sirayla \%60.0 ve \%64.8 olarak tespit edildi. Parsiyel cevap oranı GP kolunda daha fazlayd1. Ortanca progresyonsuz sağkalım (PS) 4.4 ay olup, tek değişkenli analizde GP kullanan hastalarda daha iyi PS sağlandı (5.1 ay ve 3.9 ay, $\mathrm{P}=0.01$ ) (Şekil 1). ECOG performans skoru $0-1$ olan hastalar (5.4 ay ve 4.1 ay, $\mathrm{P}=0.06$ ) ve komorbid hastalığ 1 olmayan hastalarda (5.7 ay ve 4.1 ay, $\mathrm{P}=0.06$ ) PS fark1 istatiksel anlamlı1ığa yakındı. Çok değişkenli analizde PS üzerine etkili olan değişken kombine KT kullanımıydı (Tablo 2).

Ortanca genel sağkalım (GS) 7.1 ay olup, tek değişkenli analizde tanı anında CA 199 düzeyi normal olan (10.6 ay ve 7.3 ay, $\mathrm{P}=0.04)$, ikinci basamak KT alan (12.1 ay ve 5.9 ay, $\mathrm{P}<0.001)$ hastalarda daha iyi GS saptandi. 65 yaş altında olan hastalar da ise daha iyi GS saptandı ve fark istatiksel anlamlılığa yakındı ( 8.5 ay ve 6.1 ay, $\mathrm{P}=0.08$ ). GP kombinasyonu ve $G$ alan hastalar GS açısından değerlendirildiğinde aradaki fark istatiksel olarak anlamlı değildi ( 8.3 ay ve 6.0 ay, $\mathrm{P}=0.13$ ) (Şekil 2). Çok değişkenli analizde GS için bağımsız değişkenler hastaların performans durumunun iyi olması ve ikinci basamak KT alabilmeleridir (Tablo 3).

Tablo 1: Hastaların Genel Özellikleri

\begin{tabular}{|c|c|c|c|c|}
\hline Özellikler & $\begin{array}{c}\text { Gemsitabin } \\
n=25(\%)\end{array}$ & \begin{tabular}{|} 
Gemsitabin+ \\
Sisplatin \\
$\mathrm{n}=74(\%)$
\end{tabular} & $\begin{array}{c}\text { Toplam } \\
\mathrm{n}=99(\%)\end{array}$ & $\begin{array}{c}\mathrm{P} \\
\text { değeri }\end{array}$ \\
\hline Yaş; ortanca (yıl) & $70(56-79)$ & $56.5(28-80)$ & $59(28-80)$ & $<0.001$ \\
\hline $\begin{array}{l}\text { Cinsiyet } \\
\text { Erkek } \\
\text { Kadın } \\
\end{array}$ & $\begin{array}{c}18(72.0) \\
7(28.0)\end{array}$ & $\begin{array}{l}55(74.3) \\
19(25.7) \\
\end{array}$ & $\begin{array}{l}73(73.7) \\
26(26.3)\end{array}$ & 0.81 \\
\hline $\begin{array}{l}\text { ECOG } \\
\text { performans durum } \\
\text { 0-I } \\
\text { II } \\
\end{array}$ & $\begin{array}{c}8(32.0) \\
17(68.0)\end{array}$ & $\begin{array}{l}49(66.2) \\
25(33.8)\end{array}$ & $\begin{array}{l}57(57.6) \\
42(42.4)\end{array}$ & 0.003 \\
\hline $\begin{array}{l}\text { Sigara kullanımı } \\
\text { Evet } \\
\text { Hayır } \\
\end{array}$ & $\begin{array}{l}13(52.0) \\
12(48.0) \\
\end{array}$ & $\begin{array}{l}47(63.5) \\
27(36.5) \\
\end{array}$ & $\begin{array}{l}60(60.6) \\
39(39.4) \\
\end{array}$ & 0.30 \\
\hline $\begin{array}{l}\text { Diyabetes } \\
\text { Mellitus } \\
\text { Var } \\
\text { Yok } \\
\end{array}$ & $\begin{array}{l}13(52.0) \\
12(48.0)\end{array}$ & $\begin{array}{l}26(35.1) \\
48(64.9)\end{array}$ & $\begin{array}{l}39(39.4) \\
60(60.6)\end{array}$ & 0.13 \\
\hline \begin{tabular}{|l|} 
Komorbidite \\
Var \\
Yok \\
\end{tabular} & $\begin{array}{c}17(68.0) \\
8(32.0)\end{array}$ & $\begin{array}{l}29(39.2) \\
45(60.8) \\
\end{array}$ & $\begin{array}{l}46(46.5) \\
53(53.5) \\
\end{array}$ & 0.01 \\
\hline $\begin{array}{l}\text { Tümör Yerleşim } \\
\text { Baş } \\
\text { Kuyruk } \\
\text { Gövde } \\
\text { Gövde-Kuyruk } \\
\text { Baş-Gövde } \\
\end{array}$ & $\begin{array}{c}10(40.0) \\
6(24.0) \\
5(20.0) \\
3(12.0) \\
1(4.0)\end{array}$ & $\begin{array}{c}39(52.7) \\
14(18.9) \\
14(18.9) \\
5(6.8) \\
2(2.7) \\
\end{array}$ & $\begin{array}{c}49(49.5) \\
20(20.2) \\
19(19.2) \\
8(8.1) \\
3(3.0) \\
\end{array}$ & 0.80 \\
\hline $\begin{array}{l}\text { Bazal CEA } \\
\text { Normal } \\
\text { Yüksek } \\
\text { Bilinmiyor } \\
\end{array}$ & $\begin{array}{c}10(40.0) \\
14(56.0) \\
1(4.0) \\
\end{array}$ & $\begin{array}{c}27(36.5) \\
43(58.1) \\
4(5.4)\end{array}$ & $\begin{array}{c}37(37.4) \\
57(57.6) \\
5(5.1) \\
\end{array}$ & 0.92 \\
\hline $\begin{array}{l}\text { Bazal CA 19-9 } \\
\text { Normal } \\
\text { Yüksek }\end{array}$ & $\begin{array}{c}3(12.0) \\
20(80.0)\end{array}$ & $\begin{array}{l}12(16.2) \\
58(78.4)\end{array}$ & $\begin{array}{l}15(15.1) \\
78(78.8)\end{array}$ & 0.87 \\
\hline
\end{tabular}

Adress for correspondence: Gökmen Umut Erdem, Kocaeli Derince Eğitim ve Araştırma Hastanesi Kocaeli - Türkiye 


\begin{tabular}{|c|c|c|c|c|}
\hline Bilinmiyor & $2(8.0)$ & $4(5.4)$ & $6(6.0)$ & \\
\hline Metastaz Yeri & & & & \\
\hline Karaciğer & $21(84.0)$ & $66(89.2)$ & 87 (87.9) & 0.49 \\
\hline Akciğer & $7(28.0)$ & $10(13.5)$ & $17(17.2)$ & 0.12 \\
\hline Periton & $5(20.0)$ & $8(10.8)$ & $13(13.1)$ & 0.30 \\
\hline $\begin{array}{l}\text { Ortalama KT } \\
\text { sayıs1 }\end{array}$ & $5(3-14)$ & $6(3-9)$ & $6(3-14)$ & 0.45 \\
\hline $\begin{array}{l}\text { Birinci Basamak } \\
\text { KT yanitı }\end{array}$ & $1(4.0)$ & $0(0.0)$ & $1(1.0)$ & \multirow{4}{*}{0.03} \\
\hline Tam cevap & $3(12.0)$ & $28(37.8)$ & $31(31.3)$ & \\
\hline Parsiyel cevap & $11(44.0)$ & $20(27.0)$ & $31(31.3)$ & \\
\hline $\begin{array}{l}\text { Stabil hastalık } \\
\text { Progresive } \\
\text { hastalık }\end{array}$ & $10(40.0)$ & $26(35.1)$ & $36(36.4)$ & \\
\hline $\begin{array}{l}\text { Íkinci basamak } \\
\text { KT }\end{array}$ & & & & \multirow{3}{*}{0.11} \\
\hline Kar & $18(720)$ & $34(45.9)$ & $\begin{array}{l}41(41.4) \\
58(58.6\end{array}$ & \\
\hline Yok & & & & \\
\hline $\begin{array}{l}\text { Serum albumin } \\
\text { (ortanca) }\end{array}$ & 3.7 & 3.8 & 4.4 & 0.60 \\
\hline $\begin{array}{l}\text { Serum kreatinin } \\
\text { (ortanca) }\end{array}$ & 0.83 & 0.80 & 0.80 & 0.44 \\
\hline $\begin{array}{l}\text { Serum bilirubin } \\
\text { (ortanca) }\end{array}$ & 0.80 & 0.80 & 0.80 & 0.44 \\
\hline Biliyer stent & $6(24.0)$ & $18(24.3)$ & $24(24.2)$ & 0.97 \\
\hline \begin{tabular}{|l} 
Derin ven \\
trombozu
\end{tabular} & $3(12.0)$ & $9(12.2)$ & $12(12.1)$ & 0.98 \\
\hline
\end{tabular}

CEA: Karsinoembriyonik antijen, CA 19-9: Karbonhidrat antijen 19-9, ECOG: Doğu Kooperatif Onkoloji Grubu (Eastern Cooperative Oncology Group), KT: Kemoterapi

Tablo 2: Progresyonsuz sağkalım için tek ve çok değişkenli analiz

\begin{tabular}{|c|c|c|c|c|}
\hline Özellikler & $\begin{array}{c}\text { Hasta } \\
\text { sayıs1 (\%) }\end{array}$ & $\begin{array}{l}\text { PS için tek } \\
\text { değişkenli } \\
\text { analiz (Ay) }\end{array}$ & $\begin{array}{c}P \\
\text { değeri }\end{array}$ & \begin{tabular}{|c|} 
Çok \\
değişkenli \\
analiz \\
\end{tabular} \\
\hline $\begin{array}{l}\text { Yaş (yıl) } \\
<65 \\
\geq 65 \\
\end{array}$ & $\begin{array}{l}64(64.6) \\
35(35.4) \\
\end{array}$ & $\begin{array}{l}5.1 \\
4.2\end{array}$ & 0.39 & \\
\hline \begin{tabular}{|l|} 
Cinsiyet \\
Erkek \\
Kadın \\
\end{tabular} & $\begin{array}{l}73(73.7) \\
26(26.3) \\
\end{array}$ & $\begin{array}{l}4.3 \\
5.2 \\
\end{array}$ & 0.56 & \\
\hline \begin{tabular}{|l|} 
ECOG \\
performans \\
durum \\
$0-1$ \\
$2-3$ \\
\end{tabular} & $\begin{array}{l}57(57.6) \\
42(42.4)\end{array}$ & $\begin{array}{l}5.4 \\
4.1\end{array}$ & 0.06 & $\begin{array}{c}\mathrm{P}=0.24 \\
1.29(0.838 \\
2.016)\end{array}$ \\
\hline \begin{tabular}{|l|} 
Sigara kullanımı \\
Evet \\
Hayır \\
\end{tabular} & \begin{tabular}{|l|l|}
60 & $(60.6)$ \\
$39(39.4)$ \\
\end{tabular} & $\begin{array}{l}4.8 \\
4.2 \\
\end{array}$ & 0.37 & \\
\hline $\begin{array}{l}\text { Diyabetes } \\
\text { Mellitus } \\
\text { Var } \\
\text { Yok }\end{array}$ & $\begin{array}{l}39(39.4) \\
60(60.6)\end{array}$ & $\begin{array}{l}4.3 \\
4.7\end{array}$ & 0.26 & \\
\hline \begin{tabular}{|l|} 
Komorbidite \\
Var \\
Yok \\
\end{tabular} & $\begin{array}{l}46(46.5) \\
53(53.5) \\
\end{array}$ & $\begin{array}{l}4.1 \\
5.7 \\
\end{array}$ & 0.06 & $\begin{array}{c}\mathrm{P}=0.33 \\
1.24(.796- \\
1.938) \\
\end{array}$ \\
\hline $\begin{array}{l}\text { Tümör Yerleşim } \\
\text { Baş } \\
\text { Kuyruk } \\
\text { Gövde } \\
\text { Gövde-Kuyruk } \\
\text { Baş-Gövde } \\
\end{array}$ & \begin{tabular}{|c|}
$49(49.5)$ \\
$20(20.2)$ \\
$19(19.2)$ \\
$8(8.1)$ \\
$3(3.0)$ \\
\end{tabular} & $\begin{array}{l}4.6 \\
3.8 \\
4.7 \\
3.9 \\
4.4\end{array}$ & 0.97 & \\
\hline Bazal CEA & & & & \\
\hline
\end{tabular}

\begin{tabular}{|c|c|c|c|c|}
\hline $\begin{array}{l}\text { Normal } \\
\text { Yüksek } \\
\text { Bilinmiyor }\end{array}$ & $\begin{array}{c}37(37.4) \\
57(57.6) \\
6(5.1)\end{array}$ & $\begin{array}{l}4.8 \\
4.3\end{array}$ & 0.40 & \\
\hline $\begin{array}{l}\text { Bazal CA 19-9 } \\
\text { Normal } \\
\text { Yüksek } \\
\text { Bilinmiyor } \\
\end{array}$ & $\begin{array}{c}15(15.1) \\
78(78.8) \\
6(6.0) \\
\end{array}$ & $\begin{array}{l}6.4 \\
4.4\end{array}$ & 0.17 & \\
\hline $\begin{array}{l}\text { Kemoterapi } \\
\text { Gemsitabin } \\
\text { Gemsitabin+ } \\
\text { Sisplatin }\end{array}$ & $\begin{array}{l}25(25.3) \\
74(74.7)\end{array}$ & $\begin{array}{l}3.9 \\
5.1\end{array}$ & 0.01 & $\begin{array}{c}\mathrm{P}=0.02 \\
1.7(1.087- \\
2.792)\end{array}$ \\
\hline $\begin{array}{l}\text { İkinci basamak } \\
\text { KT } \\
\text { Var } \\
\text { Yok } \\
\end{array}$ & $\begin{array}{l}41(41.4) \\
58(58.6)\end{array}$ & $\begin{array}{l}5.6 \\
4.2\end{array}$ & 0.52 & \\
\hline $\begin{array}{l}\text { Serum albumin } \\
\text { (ortanca) } \\
<3.8 \\
\geq 3.8 \\
\end{array}$ & $\begin{array}{l}49(49.5) \\
50(50.5)\end{array}$ & $\begin{array}{l}4.2 \\
4.7\end{array}$ & 0.63 & \\
\hline $\begin{array}{l}\text { Serum kreatinin } \\
\text { (ortanca) } \\
<0.8 \\
\geq 0.8 \\
\end{array}$ & $\begin{array}{l}45(45.5) \\
54(54.5)\end{array}$ & $\begin{array}{l}4.7 \\
4.0\end{array}$ & 0.35 & \\
\hline $\begin{array}{l}\text { Serum bilirubin } \\
\text { (ortanca) } \\
<0.8 \\
\geq 0.8\end{array}$ & $\begin{array}{l}47(47.5) \\
52(52.5)\end{array}$ & $\begin{array}{l}4.6 \\
4.3\end{array}$ & 0.33 & \\
\hline $\begin{array}{l}\text { Derin ven } \\
\text { trombozu } \\
\text { Yok } \\
\text { Var } \\
\end{array}$ & $\begin{array}{l}87(87.9) \\
12(12.1)\end{array}$ & $\begin{array}{l}4.7 \\
3.5\end{array}$ & 0.37 & \\
\hline $\begin{array}{l}\text { Biliyer stent } \\
\text { Yok } \\
\text { Var }\end{array}$ & $\begin{array}{l}75(75.8) \\
24(24.2) \\
\end{array}$ & $\begin{array}{l}4.6 \\
4.1 \\
\end{array}$ & 0.78 & \\
\hline
\end{tabular}

CEA: Karsinoembriyonik antijen, CA 19-9:

Karbonhidrat antijen 19-9, ECOG: Doğu Kooperatif Onkoloji Grubu (Eastern Cooperative Oncology Group), KT: Kemoterapi, PS: Progresyonsuz sağkalım

Tablo 3: Genel sağkalım için tek ve çok değişkenli analiz

\begin{tabular}{|c|c|c|c|c|}
\hline Özellikler & $\begin{array}{c}\text { Hasta say1s1 } \\
(\%)\end{array}$ & $\begin{array}{c}\text { GS için } \\
\text { tek } \\
\text { değişkenli } \\
\text { analiz } \\
\text { (Ay) }\end{array}$ & $\begin{array}{l}P \\
\text { değeri }\end{array}$ & $\begin{array}{c}\text { Çok } \\
\text { değişkenli } \\
\text { analiz }\end{array}$ \\
\hline $\begin{array}{l}\text { Yaş (y1l) } \\
<65 \\
\geq 65\end{array}$ & $\begin{array}{l}64(64.6) \\
35(35.4)\end{array}$ & $\begin{array}{l}8.5 \\
6.1\end{array}$ & 0.08 & $\begin{array}{c}\mathrm{P}=0.92 \\
0.97 \\
(0.580- \\
1.637)\end{array}$ \\
\hline \begin{tabular}{|l} 
Cinsiyet \\
Erkek \\
Kadın
\end{tabular} & $\begin{array}{l}73(73.7) \\
26(26.3)\end{array}$ & $\begin{array}{l}6.4 \\
8.3\end{array}$ & 0.48 & \\
\hline \begin{tabular}{|l} 
ECOG \\
performans \\
durum \\
$0-1$ \\
$2-3$
\end{tabular} & $\begin{array}{l}57(57.6) \\
42(42.4)\end{array}$ & $\begin{array}{l}8.3 \\
6.3\end{array}$ & 0.15 & $\begin{array}{c}\mathrm{P}=0.02 \\
1.66 \\
(1.077- \\
2.585)\end{array}$ \\
\hline $\begin{array}{l}\text { Sigara } \\
\text { kullanımı } \\
\text { Evet } \\
\text { Hayır } \\
\end{array}$ & $\begin{array}{l}60(60.6) \\
39(39.4)\end{array}$ & $\begin{array}{l}8.4 \\
6.7\end{array}$ & 0.47 & \\
\hline
\end{tabular}

Adress for correspondence: Gökmen Umut Erdem, Kocaeli Derince Eğitim ve Araştırma Hastanesi Kocaeli - Türkiye 


\begin{tabular}{|c|c|c|c|c|}
\hline \begin{tabular}{|l} 
Diyabetes \\
Mellitus \\
Var \\
Yok \\
\end{tabular} & $\begin{array}{l}39(39.4) \\
60(60.6)\end{array}$ & $\begin{array}{l}6.7 \\
8.3\end{array}$ & 0.18 & \\
\hline $\begin{array}{l}\text { Komorbidite } \\
\text { Var } \\
\text { Yok }\end{array}$ & $\begin{array}{l}46(46.5) \\
53(53.5)\end{array}$ & $\begin{array}{l}6.3 \\
8.8\end{array}$ & 0.11 & $\begin{array}{c}\mathrm{P}=0.72 \\
0.91 \\
(0.562- \\
1.497) \\
\end{array}$ \\
\hline \begin{tabular}{|l} 
Tümör \\
Yerleşim \\
Baş \\
Kuyruk \\
Gövde \\
Gövde- \\
Kuyruk \\
Baş-Gövde
\end{tabular} & $\begin{array}{c}49(49.5) \\
20(20.2) \\
19(19.2) \\
8(8.1) \\
3(3.0)\end{array}$ & $\begin{array}{l}8.8 \\
5.0 \\
8.0 \\
5.7 \\
5.5\end{array}$ & 0.57 & \\
\hline \begin{tabular}{|l|} 
Bazal CEA \\
Normal \\
Yüksek \\
Bilinmiyor
\end{tabular} & $\begin{array}{c}37(37.4) \\
57(57.6) \\
5(5.1)\end{array}$ & $\begin{array}{l}8.0 \\
7.3\end{array}$ & 0.26 & \\
\hline \begin{tabular}{|l} 
Bazal CA 19-9 \\
Normal \\
Yüksek \\
Bilinmiyor \\
\end{tabular} & $\begin{array}{c}15(15.1) \\
78(78.8) \\
6(6.0) \\
\end{array}$ & $\begin{array}{c}10.6 \\
7.3\end{array}$ & 0.04 & $\begin{array}{c}\mathrm{P}=0.14 \\
1.59 \\
(0.845- \\
3.016)\end{array}$ \\
\hline $\begin{array}{l}\text { Kemoterapi } \\
\text { Gemsitabin } \\
\text { Gemsitabin+ } \\
\text { Sisplatin }\end{array}$ & $\begin{array}{l}25(25.3) \\
74(74.7)\end{array}$ & $\begin{array}{l}6.0 \\
8.3\end{array}$ & 0.13 & $\begin{array}{c}\mathrm{P}=0.76 \\
1.08 \\
(0.651- \\
1.800)\end{array}$ \\
\hline $\begin{array}{l}\text { İkinci basamak } \\
\text { KT } \\
\text { Var } \\
\text { Yok } \\
\end{array}$ & $\begin{array}{l}41(41.4) \\
58(58.6)\end{array}$ & $\begin{array}{c}12.1 \\
5.9\end{array}$ & $<0.001$ & $\begin{array}{c}\mathrm{P}<0.001 \\
2.56 \\
(1.616- \\
4.000) \\
\end{array}$ \\
\hline $\begin{array}{l}\text { Serum } \\
\text { albumin } \\
\text { (ortanca) } \\
<3.8 \\
\geq 3.8 \\
\end{array}$ & $\begin{array}{l}49(49.5) \\
50(50.5)\end{array}$ & $\begin{array}{l}7.6 \\
6.7\end{array}$ & 0.31 & \\
\hline $\begin{array}{l}\text { Serum } \\
\text { kreatinin } \\
\text { (ortanca) } \\
<0.8 \\
\geq 0.8 \\
\end{array}$ & $\begin{array}{l}45(45.5) \\
54(54.5)\end{array}$ & $\begin{array}{l}8.7 \\
6.1\end{array}$ & 0.22 & \\
\hline $\begin{array}{l}\text { Serum } \\
\text { bilirubin } \\
\text { (ortanca) } \\
<0.8 \\
\geq 0.8 \\
\end{array}$ & $\begin{array}{l}47(47.5) \\
52(52.5)\end{array}$ & $\begin{array}{l}6.3 \\
7.3\end{array}$ & 0.27 & \\
\hline $\begin{array}{l}\text { Derin ven } \\
\text { trombozu } \\
\text { Yok } \\
\text { Var } \\
\end{array}$ & $\begin{array}{l}87(87.9) \\
12(12.1)\end{array}$ & $\begin{array}{l}7.1 \\
5.6\end{array}$ & 0.86 & \\
\hline $\begin{array}{l}\text { Biliyer Stent } \\
\text { Yok } \\
\text { Var }\end{array}$ & $\begin{array}{l}75(75.8) \\
24(24.2)\end{array}$ & $\begin{array}{l}6.7 \\
8.9\end{array}$ & 0.92 & \\
\hline
\end{tabular}

CEA: Karsinoembriyonik antijen, CA 19-9:

Karbonhidrat antijen 19-9, ECOG: Doğu Kooperatif Onkoloji Grubu (Eastern Cooperative Oncology Group), KT: Kemoterapi, PS: Progresyonsuz sağkalım

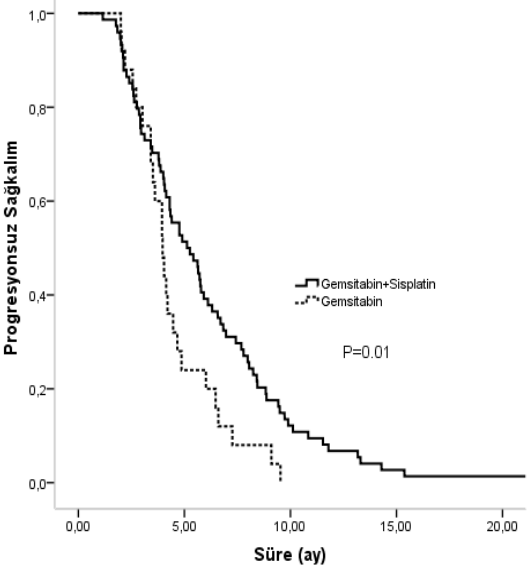

Figür 1: Gemsitabin-Sisplatin ile Gemsitabin alan hastaların progresyonsuz sağkalım eğrileri

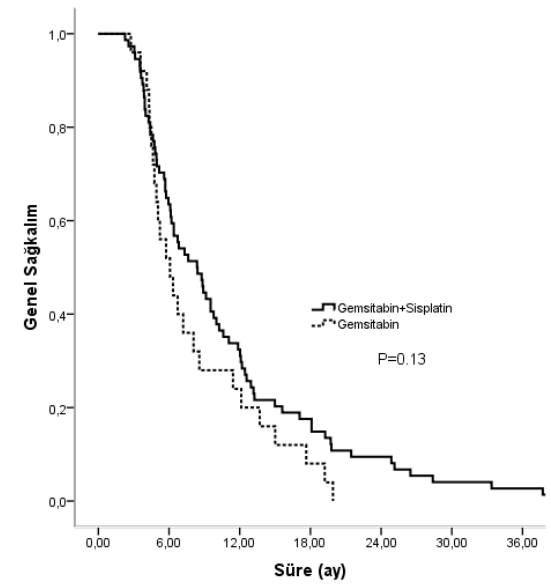

Figür 2: Gemsitabin-Sisplatin ile Gemsitabin alan hastaların genel sağkalım eğrileri

\section{TARTIŞMA}

Pankreas kanseri kemoresistan kanserlerden birisidir. Lokal ileri ve metastatik pankreas kanserli hastalarda G ile \%5.4-\%10.1 objektif cevap oranlar1, \%28.0-\%48.5 hastalık kontrol oranları sağlanırken (9-13), GP ile bu oran sırası ile \%4.8-\%31.0 ve \%33.4-\% 75.0 arasindadir (911, 13-16). Bu çalışmalarda GP'nin tek başına G'ye oranla daha yüksek cevap oranlarına (10) sahip olduğu gösterilmekle birlikte benzer etkinlikte olduğu da gösterilmiştir $(9,11,13)$. Çalışmamızda da GP tek başına G ile karşılaştırıldığında daha iyi objektif cevap oranlarına (\%37.8 \& \% 16.0) sahip iken, hastalık kontrol oranları (\%64.8 \& \%60.0) arasinda fark saptanmadi. Calıșmamızda objektive cevap oranlarımızın daha yüksek olmasının sebebi; 
çalışmaya en az 3 kür KT alan hastaların dahil edilmesi ile ilişskili olabilir.

Gemsitabin ve sisplatin

kombinasyonunun PS ve GS üzerine etkinliği açısından farklı veriler mevcuttur. Colucci ve arkadaşları (10) tarafindan yapılan bir çalışmada GP kombinasyonu tek başına G'den daha uzun PS (20 hafta \& 8 hafta, $\mathrm{P}=0.04$ ) avantaj1 sağlarken, GS istatiksel olarak anlamlı değildi. Takibinde yapılan başka bir faz 3 çalışmada da lokal ileri hastalıkta kombinasyon kolunda PS (8.6 ay \& 3.2 ay) fark1 saptanırken, metastatik hastalikta PS (4.2 ay \& 3.1 ay) ve GS (7.2 ay \& 4.7 ay) fark 1 saptanmad 1 (11). Takibinde yapılan çalışmalarda GP kombinasyonu cevap oran1, klinik yarar ve sağkalım açısından bir avantaj sağlamadığı gösterilmiştir $(9, \quad 13,17)$ Yapılan metaanalizlerde de kombinasyon KT'si G monoterapsi ile karşılaştırıldığında sağkalım yarar1 gösteren $(6,18)$ yada göstermeyen $(7,8$, 19) sonuçlar mevcuttur. Bu çalışmalarda GP ile 3.6 ay-7.4 ay arasinda PS ve 6.8-9.6 arasinda GS, sadece G ile 1.8-4.6 arasinda PS ve 4.6-8.3 arasında GS sağlanmıștır (9-11, 13-16). Bizim çalışmamızda ise tek başına $G$ yerine GP teavisi verilmesi PS açısından avantaj sağlarken, GS avantaj1 göstermemiştir. Monoterapi ve kombinasyon kolunda elde edilen sağkalım verilerimiz literatür ile uyumluydu.

Literatür incelendiğinde yapılan çalışmalarda kombinasyon kolunda sağkalım farkının lokal ileri hastalıkta $(11,20)$ ve ECOG performans skoru (11) daha iyi olan hastalarda anlamlı olduğu gösterilmiştir. $\mathrm{Bu}$ nedenle çalışmamıza sadece metastatik hasta grubu alındı ve daha uzun PS sağlayan bağımsız değişken kombinasyon şeklinde KT verilmesi (5.1 ay \& 3.9 ay), daha uzun GS sağlayan faktörler ise literatür ile uyumlu olarak ECOG performans skorunun daha iyi olmas1 (8.3 ay \& 6.3 ay) ve ikinci basmak KT almış olmalarıdır (12.1 ay \& 5.9 ay).

BRCA ile ilişkili pankreatik duktal adenokarsinomalı hastaların standart tedaviye platin ajanlarının eklenmesinden fayda görebileceği gösterilmiştir (21). Çalışmamızda ise hastaların BRCA ilişkili mutasyon durumu incelenmemiş olması çalışmamızdaki kısıtlayıcı durumdur. Çalışmamızın diğer kısıtlayıcı durumları; retrospektif doğası gereği hematolojik grade 3-4 toksisite dişında toksisitenin ve doz azaltımının değerlendirilememesi, yine retrospektif doğas1 gereği daha güncel tedavilerin verilememiş olmasidir.

\section{SONUÇ}

Metastatik pankreas kanserli hastalarda gemsitabin ve sisplatin kombinasyon tedavisi tek ajan gemsitabine göre genel sağkalımda anlamlı iyileşme sağlamasa da daha iyi progresyonsuz sağkalım avantaj1 sağlamaktadır. Tanı anında ECOG performas durumunun iyi olan, ikinci basamak KT alabilen hastalar daha iyi genel sağkalıma sahiptir.

Çıkar Çatışması: Yok

\section{REFERANSLAR}

1. Surveillance, Epidemiology, and End Results Program. SEER stat facts sheets: pancreas cancer. [Accessed September 15, 2016]. updated 2016. Available from: http://seer.cancer.gov/statfacts/html/pancr eas.html

2. Ducreux M, Cuhna AS, Caramella C, Hollebecque A, Burtin P, Goere D, et al. Cancer of the pancreas: ESMO Clinical Practice Guidelines for diagnosis, treatment and follow-up. Annals of oncology: official journal of the European Society for Medical Oncology. 2015 Sep;26 Suppl 5:v56-68. PubMed PMID: 26314780.

3. Tempero MA, Malafa MP, Al-Hawary M, Asbun H, Bain A, Behrman SW, et al. Pancreatic Adenocarcinoma, Version 2.2017, NCCN Clinical Practice Guidelines in Oncology. Journal of the National Comprehensive Cancer Network: JNCCN. $2017 \quad$ Aug;15(8):1028-61 . PubMed PMID: 28784865.

4. Bergman AM, Ruiz van Haperen VW, Veerman G, Kuiper CM, Peters GJ. Synergistic interaction between cisplatin and gemcitabine in vitro. Clinical cancer research: an official journal of the American Association for Cancer Research. 1996 Mar;2(3):521-30. PubMed PMID: 9816199.

5. Peters GJ, Bergman AM, Ruiz van Haperen VW, Veerman G, Kuiper CM, Braakhuis BJ. Interaction between cisplatin and gemcitabine in vitro and in 
vivo. Seminars in oncology. 1995 Aug;22(4 Suppl 11):72-9. PubMed PMID: 7481849.

6. Sultana A, Smith CT, Cunningham D, Starling N, Neoptolemos JP, Ghaneh P. Meta-analyses of chemotherapy for locally advanced and metastatic pancreatic cancer. Journal of clinical oncology: official journal of the American Society of Clinical Oncology. 2007 Jun 20;25(18):2607-15. PubMed PMID: 17577041.

7. $\mathrm{Hu}$ J, Zhao G, Wang HX, Tang L, Xu YC, $\mathrm{Ma} \mathrm{Y}$, et al. A meta-analysis of gemcitabine containing chemotherapy for locally advanced and metastatic pancreatic adenocarcinoma. Journal of hematology \& oncology. 2011 Mar 26;4:11. PubMed PMID: 21439076. Pubmed Central PMCID: 3079694.

8. Xie de R, Liang HL, Wang Y, Guo SS. Meta-analysis of inoperable pancreatic cancer: gemcitabine combined with cisplatin versus gemcitabine alone. Chinese journal of digestive diseases. 2006;7(1):49-54. PubMed PMID: 16412038.

9. Chao Y, Wu CY, Wang JP, Lee RC, Lee WP, Li CP. A randomized controlled trial of gemcitabine plus cisplatin versus gemcitabine alone in the treatment of metastatic pancreatic cancer. Cancer chemotherapy and pharmacology. 2013 Sep;72(3):637-42. PubMed PMID: 23912692.

10. Colucci G, Giuliani F, Gebbia V, Biglietto M, Rabitti P, Uomo G, et al. Gemcitabine alone or with cisplatin for the treatment of patients with locally advanced and/or metastatic pancreatic carcinoma: a prospective, randomized phase III study of the Gruppo Oncologia dell'Italia Meridionale. Cancer. 2002 Feb 15;94(4):902-10. PubMed PMID: 11920457.

11. Heinemann V, Quietzsch D, Gieseler F, Gonnermann M, Schonekas H, Rost A, et al. Randomized phase III trial of gemcitabine plus cisplatin compared with gemcitabine alone in advanced pancreatic cancer. Journal of clinical oncology: official journal of the American Society of Clinical Oncology. 2006 Aug 20;24(24):3946-52. PubMed PMID: 16921047.

12. Burris HA, 3rd, Moore MJ, Andersen J, Green MR, Rothenberg ML, Modiano MR, et al. Improvements in survival and clinical benefit with gemcitabine as first-line therapy for patients with advanced pancreas cancer: a randomized trial. Journal of clinical oncology : official journal of the American Society of Clinical Oncology. 1997 Jun;15(6):2403-13. PubMed PMID: 9196156.

13. Colucci G, Labianca R, Di Costanzo F, Gebbia V, Carteni G, Massidda B, et al. Randomized phase III trial of gemcitabine plus cisplatin compared with single-agent gemcitabine as first-line treatment of patients with advanced pancreatic cancer: the GIP-1 study. Journal of clinical oncology : official journal of the American Society of Clinical Oncology. 2010 Apr 01;28(10):1645-51. PubMed PMID: 20194854.

14. Heinemann V, Wilke $H$, Mergenthaler HG, Clemens $\mathrm{M}$, Konig $\mathrm{H}$, Illiger $\mathrm{HJ}$, et al. Gemcitabine and cisplatin in the treatment of advanced or metastatic pancreatic cancer. Annals of oncology : official journal of the European Society for Medical Oncology. 2000 Nov;11(11):1399-403. PubMed PMID: 11142479.

15. Philip PA, Zalupski MM, Vaitkevicius VK, Arlauskas P, Chaplen R, Heilbrun LK, et al. Phase II study of gemcitabine and cisplatin in the treatment of patients with advanced pancreatic carcinoma. Cancer. 2001 Aug 01;92(3):569-77. PubMed PMID: 11505401.

16. Brodowicz T, Wolfram RM, Kostler WJ, Tomek S, Vaclavik I, Steger GG, et al. Phase II study of gemcitabine in combination with cisplatin in patients with locally advanced and/or metastatic pancreatic cancer. Anti-cancer drugs. 2000 Sep;11(8):623-8. PubMed PMID: 11081453. 